\title{
Autonomous valve for detection of biopolymer degradation
}

Keller, Stephan Urs; Noeth, Nadine-Nicole; Fetz, Stefanie; Grünefeld, Marco; Geschke, Oliver; Boisen, Anja; Haefliger, D.

Published in:

Sensors, 2009 IEEE

Link to article, DOI:

10.1109/ICSENS.2009.5398241

Publication date:

2009

Document Version

Publisher's PDF, also known as Version of record

Link back to DTU Orbit

Citation (APA):

Keller, S. U., Noeth, N-N., Fetz, S., Grünefeld, M., Geschke, O., Boisen, A., \& Haefliger, D. (2009). Autonomous valve for detection of biopolymer degradation. In Sensors, 2009 IEEE (pp. 375-378). IEEE.

https://doi.org/10.1109/ICSENS.2009.5398241

\section{General rights}

Copyright and moral rights for the publications made accessible in the public portal are retained by the authors and/or other copyright owners and it is a condition of accessing publications that users recognise and abide by the legal requirements associated with these rights.

- Users may download and print one copy of any publication from the public portal for the purpose of private study or research.

- You may not further distribute the material or use it for any profit-making activity or commercial gain

- You may freely distribute the URL identifying the publication in the public portal

If you believe that this document breaches copyright please contact us providing details, and we will remove access to the work immediately and investigate your claim 


\section{Autonomous Valve for Detection of Biopolymer Degradation}

\author{
Stephan Keller, Nadine Noeth, Stefanie Fetz, Marco \\ Grünefeld, Oliver Geschke, Anja Boisen \\ DTU Nanotech - Department of Micro- and Nanotechnology \\ Technical University of Denmark \\ Kgs. Lyngby, Denmark \\ Stephan.keller@nanotech.dtu.dk
}

\author{
Daniel Haefliger \\ Sensirion \\ Staefa, Switzerland
}

\begin{abstract}
We present a polymer microvalve that allows the detection of biopolymer degradation without the need of external energy. The valve is based on a polymer container filled with a colored marker solution and closed by a thin lid. This structure is covered by a film of poly(L-lactide) and degradation of the biopolymer triggers the release of the color which is detected visually. The autonomous valve has potential for the fast testing of biopolymer degradation under various environmental conditions or by specific enzymes.
\end{abstract}

\section{INTRODUCTION}

Biopolymers are materials that are synthesized from natural resources such as starch, cellulose or chitin and that are degraded by hydrolysis or enzymatic activity in the environment [1]. Recently, biopolymers were introduced for packaging or the fabrication of implants, replacing traditional polymers. A large number of biopolymers have been synthesized and many are already commercially available e.g. Polycaprolactone (PCL), Polylactic acid (PLA) and Polyhydroxybutyrate (PHB). However, the identification of the mechanisms and conditions of biodegradation for the different polymers is tedious. Typically, biopolymer degradation is evaluated by the measurement of the weight loss of macro-sized samples exposed to various environmental conditions for several weeks or months [2]. Therefore, the establishment of simple methods for faster detection of biodegradation is of high interest. Here, we present a new sensor concept based on a polymer valve. The novelty of the sensor is that the read-out is autonomous, which means that no external energy source is required. The focus of this work was on the design and fabrication of the autonomous sensor.

\section{SENSOR PRINCIPLE}

The principle of the autonomous valve is illustrated in Fig. 1. The core part of this device is a microcontainer filled with a colored marker solution and closed by a thin polymer lid. The lid is sealed with a thin film of biopolymer. Specific degradation of the biopolymer results in mechanical bending of the lid due to residual stress, whereby the marker solution is released. This color change is detected by the naked eye or with an optical microscope. Earlier, the autonomous release of liquids was demonstrated by the etching of a thin metal film [3]. Compared to this, the actuation of the valve by degradation of a thin biopolymer film is the first bioapplication of the sensor concept. A major challenge is that a large actuation of the lid is required to release the colored marker. Also, the container needs to be completely sealed until the degradation of the biopolymer occurs.

\section{MATERIALS AND METHODS}

\section{A. Design of autonomous valve}

For proof-of-concept of the device, a microfluidic chip was designed as shown in Fig. 2. The chip has a total size of 1 $\mathrm{x} 1 \mathrm{~cm}^{2}$ to provide enough area for microfluidic connections. The lid with a base length of $400 \mu \mathrm{m}$ was placed in the center of the chip to allow for observation with an optical microscope. The microfluidic chip was fabricated using three layers of the negative epoxy photoresist SU-8. The advantage of this polymer is the possibility of combined fabrication of both mechanical structures such as cantilevers and microfluidic channels [4]. The Young's modulus of SU-8 is about 50 times lower compared to traditional Si-based materials [5]. This results in a highly flexible lid if the thickness of the polymer is in the micrometer range. Therefore, the thickness of the first SU-8 layer defining the valve was as low as $5.6 \mu \mathrm{m}$.
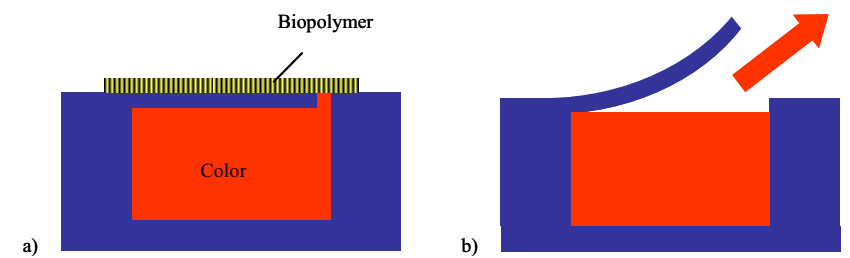

Figure 1. Principle of the autonomous valve; a) polymer lid closed by biocoating; b) degradation and color release 
The second layer of SU-8 serves as a reinforcement of the channel bottom and has a thickness of $65 \mu \mathrm{m}$. A small window is placed at the location of the valve in the center of the chip. The third layer has a thickness of $250 \mu \mathrm{m}$. The design includes a U-shaped microchannel with a width of $600 \mu \mathrm{m}$ and a large circular well at each end serving as fluid inlet and outlet. Circular holes with a diameter of $200 \mu \mathrm{m}$ were evenly distributed on the chip area to allow release of the film stress in the thick SU-8.

\section{B. Fabrication of microfluidic chip}

The fabrication process is summarized in Fig. 3. First, a fluorocarbon release coating was deposited on a standard Sisubstrate using the passivation cycle in a deep reactive ion etch device (ASE, STS technology, UK). The parameters for the plasma polymerization were optimized to allow the release of thin SU-8 films [6]. Then, SU-8 2005 (MicroChem, USA) was spin-coated (RC8-THP, Karl Süss, Germany) to a thickness of 5,6 $\mu \mathrm{m}$. The processing of the thin SU-8 film was redesigned to obtain high structural stability and low residual stress in the polymer [7]. Solvent evaporation at room temperature for $2 \mathrm{~h}$ was followed by a standard UV exposure (Mask aligner MA6/BA6, Karl Süss, Germany) with a dose of $250 \mathrm{~mJ} / \mathrm{cm}^{2}$ to define the lid. The exposure parameters were optimized and a gap of only $5 \mu \mathrm{m}$ between the microfluidic channel and the lid was achieved. The resist was postexposure baked on a hotplate at $50^{\circ} \mathrm{C}$ for $1 \mathrm{~h}$ and developed in propylene glycol monomethyl ether acetate (PGMEA) for 4 min. The SU-8 structures were flood-exposed with a dose of $500 \mathrm{~mJ} / \mathrm{cm}^{2}$ and hard-baked in an oven at $90^{\circ} \mathrm{C}$ for $15 \mathrm{~h}$ to remove residual stress gradients in the SU- 8 and improve the cross-linking of the polymer. The additional hard-bake step reduced initial out-of-plane bending of the lid without affecting the release from the fluorocarbon-coated substrate [8]. Two further steps of photolithography with SU-8 2075 were performed to define the microfluidic chip with the channel simulating the liquid container as described above. A final hard-bake step in an oven at $120^{\circ} \mathrm{C}$ for $2 \mathrm{~h}$ allowed the mechanical release of the devices from the substrate using a razor blade. Fig. 4 shows the microchannel and valves with a dimension of $400 \times 400 \mu^{2}$.

\section{Biopolymer deposition}

The lid was closed by spotting $2 \mu \mathrm{l}$ of a 2 wt.\%-solution poly(L-lactide) (PLLA 2002D, NatureWorks, USA) dissolved in dichloromethane on top of the structure. Fig. 5 shows the lid after deposition of the PLLA. The thickness of the coating is about $10 \mu \mathrm{m}$ and the biopolymer perfectly seals the underlying microchannel.

\section{Microfluidic test setup}

For the evaluation of biopolymer degradation, a microfluidic test setup was designed. The complete assembly of the different parts of the microfluidic setup and the fluid flow are schematically represented in Fig. 6. First, a $5 \mathrm{~mm}$ thick PMMA base-plate was structured with a micro-milling machine (Mini-Mill/3PRO, Minitech, USA). It includes four microfluidic inlets and four screws to tighten and seal the system. A PDMS layer is placed on top of the base plate and aligned to the inlets.

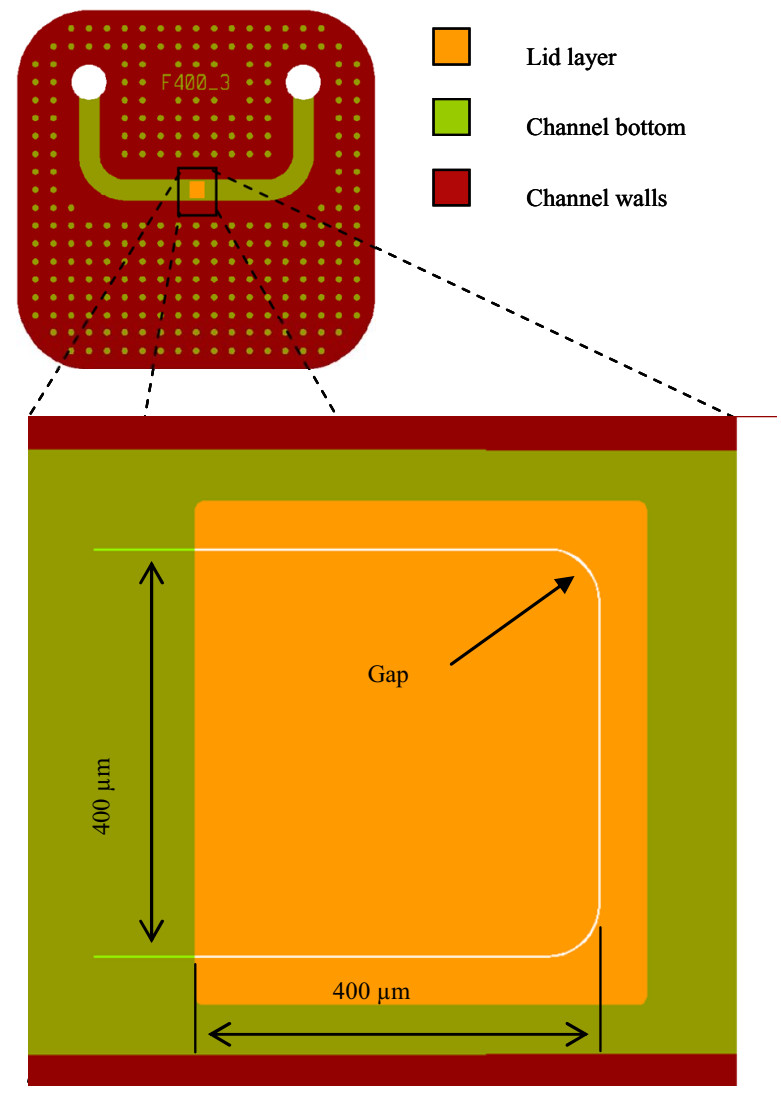

Figure 2. Design of the microfluidic chip with three layers of S U-8
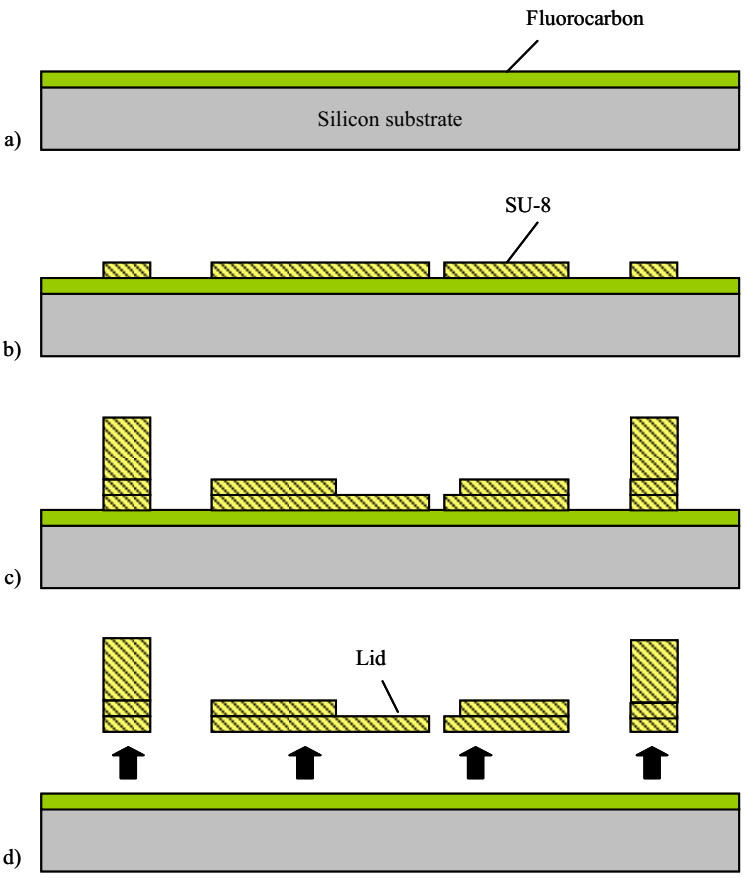

Figure 3. Fabrication of the autonomous valve: a) deposition of fluorocarbon release coating; b) Patterning of 5,5- $\mu$ m-thick SU-8 film defining the lid; c) 2 steps of SU- 8 photolithography to define the microfluidic channel; d) mechanical release of the microfluidic chip 


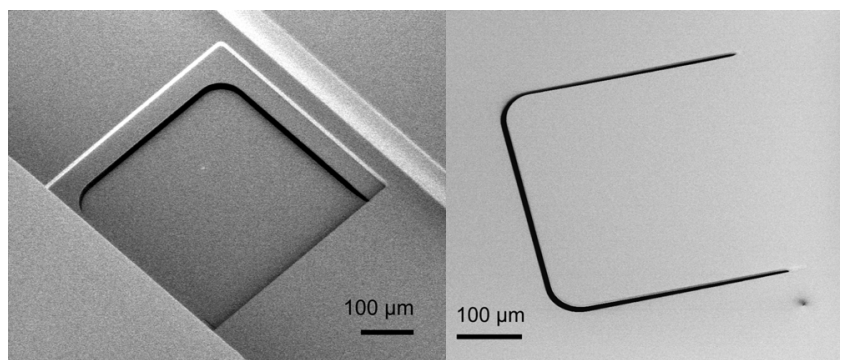

Figure 4. SU-8 lid and microchannel after release from the fluorocarbon substrate; SU-8 thickness $=5,6 \mu \mathrm{m}$; lid area $=400 \times 400 \mu \mathrm{m}^{2}$

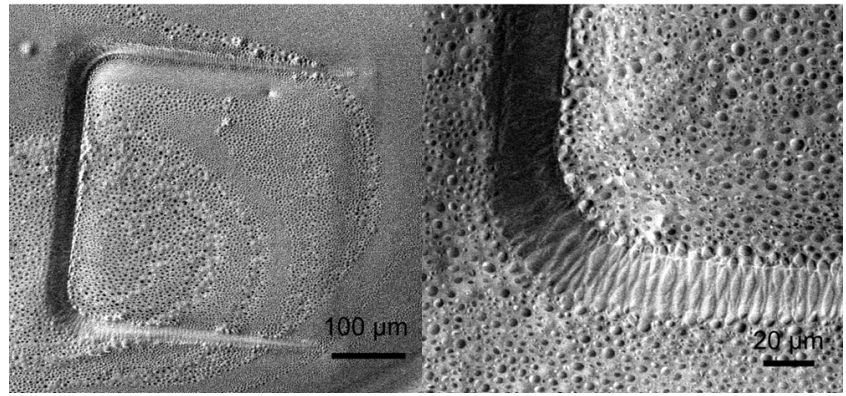

Figure 5. SU-8 lid after coating with PLLA

For this purpose, PDMS was spin-coated onto a $\mathrm{Si}$ wafer to a thickness of $300 \mu \mathrm{m}$ and annealed for $10 \mathrm{~min}$ at $85^{\circ} \mathrm{C}$. Then, a microfluidic chamber (B) and access holes for the SU8 microchannel (A) were patterned by laser machining using a $\mathrm{CO}_{2}$ laser (48-5S Duo Lase, Synrad, USA) [9]. The released microfluidic chips were closed via single chip bonding by gluing a Si tape (Arcare 91005, Adhesives Research) on top of the SU-8 channel and placed on the PDMS layer. The PDMS ensured the sealing between the PMMA base plate and the SU-8. As a counterpart, a 1,5 mm thick PMMA top plate was structured using the $\mathrm{CO}_{2}$ laser and annealed afterwards for 30 min at $85^{\circ} \mathrm{C}$ to decrease residual stress. It had a window at the position of the SU-8 chip to facilitate observation of the liquid release using an optical microscope. To avoid leakage in the microfluidic setup it was required to press the different parts of the assembly together with four screws. A glass plate had to be introduced between the top plate and the SU-8 chip to achieve a uniform pressure and to avoid breaking the SU-8 chip or the PMMA. The glass plate was prepared with a dicing saw (DAD 321, DISCO, Japan) and had a base length of 11 $\mathrm{mm}$ and a thickness of $500 \mu \mathrm{m}$. The transparency of the different components allows the observation of biopolymer degradation and liquid release with an optical microscope.

\section{E. Biopolymer degradation}

PLLA can be degraded by hydrolysis or enzymes [9]. It was shown that the degradation rate in alkaline solutions is relatively high compared to acids or enzymes [10]. Therefore, $10 \mathrm{M} \mathrm{NaOH}$ was used to hydrolyze the biopolymer for proofof-concept. The SU-8 microchannel (A) was filled with a 5 $\mathrm{mM}$ Rhodamine marker solution. Then, the $\mathrm{NaOH}$ was introduced in the microfluidic chamber (B). Fig. 7 presents the assembled microfluidic test setup with the Rhodamine introduced in the microfluidic channel (A).

\section{RESULTS}

Fig. 8 shows optical images of the autonomous valve integrated in the microfluidic system. At the start of the experiment (Fig. 8.a), the PLLA perfectly sealed the channel (A) filled with the marker solution. About $1 \mathrm{~h}$ after introduction of the $\mathrm{NaOH}$, the biopolymer was sufficiently degraded to allow the actuation of the valve (Figure 8.b-c) and the release of the Rhodamine into the microfluidic channel. After flushing with fresh $\mathrm{NaOH}$, the removal of parts of the biopolymer film was observed (Fig. 8.d).

\section{CONCLUSION AND OUTLOOK}

We have designed and fabricated an autonomous valve that was used for the detection of PLLA degradation in alkaline solution. The sensor response is relatively fast compared to traditional methods used for this purpose.

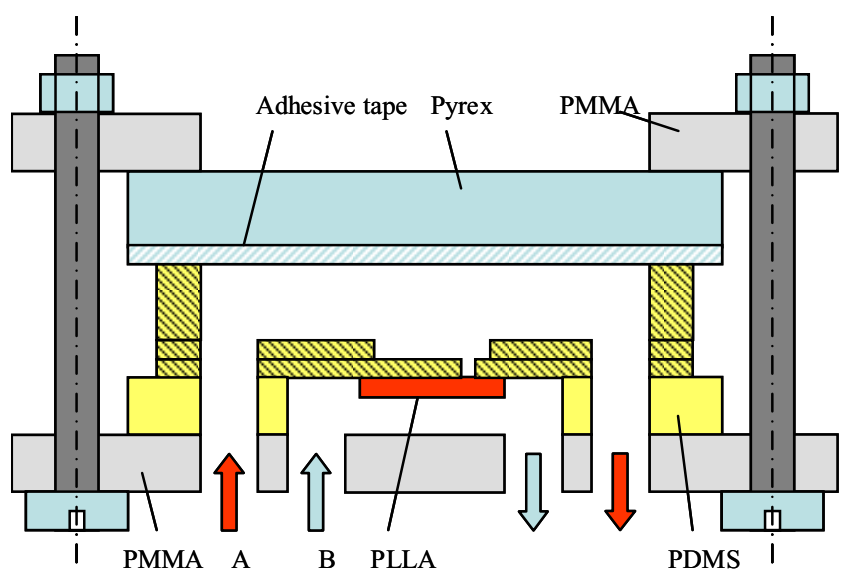

Figure 6. Schematic of the microfluidic setup with the autonomous valve and two microfluidic channels. $A=$ colored marker solution; $B=\mathrm{NaOH}$

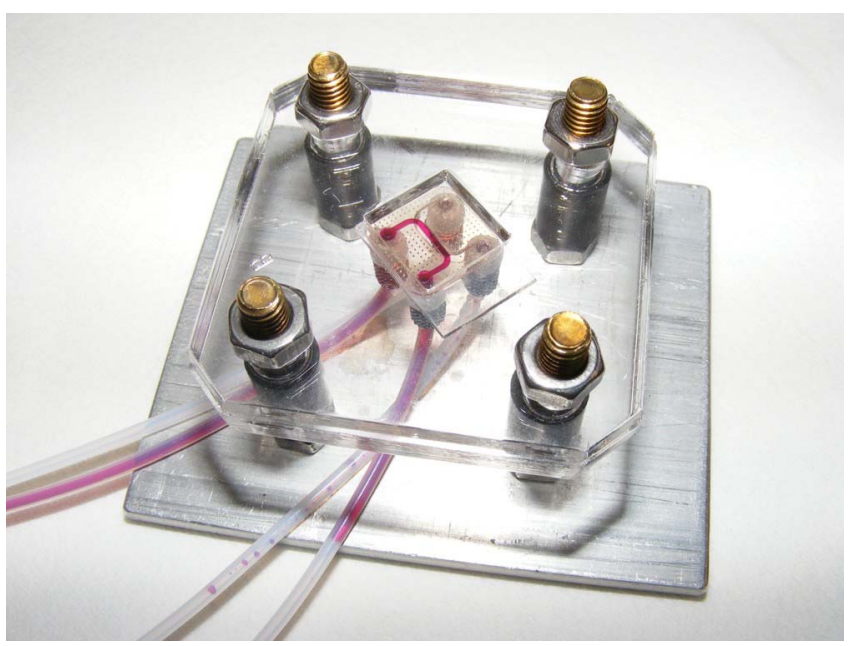

Figure 7. Microfluidic setup 

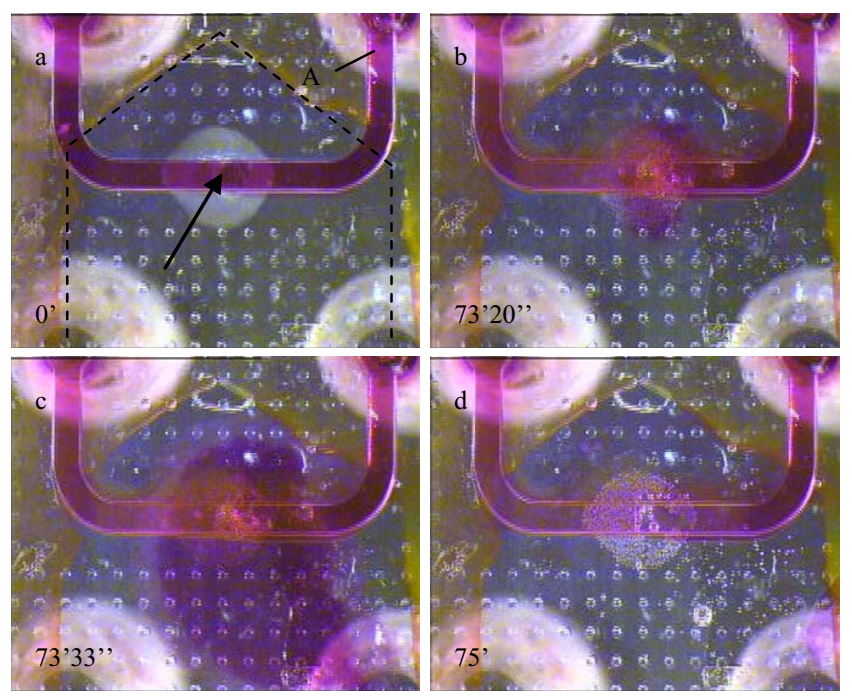

Figure 8. Top view of the microfluidic setup at different times after introduction of the $\mathrm{NaOH}$. The valve covered with the biopolymer is in the center (arrow). The top channel is filled with marker solution (A), the microfluidic chamber below (interrupted line) is filled with $\mathrm{NaOH}$. a)-c) degradation of the PLLA; d) flushing with fresh $\mathrm{NaOH}$ shows that the biopolymer is removed

The read-out is done visually, without the requirement of external energy sources. It is clear that the new approach is unable to provide information about the exact degradation mechanisms or the mass loss of the polymer. However, the method can be used for a fast qualitative evaluation of biopolymer degradation as the concept can easily be extended to other biopolymers and other degradation conditions. In near future, the $\mathrm{NaOH}$ will be substituted by enzymatic solutions for degradation of the PLLA. Furthermore, coating of the valve with other biopolymers is planned. The fabrication of arrays of autonomous valves allows parallel testing which even further increases the throughput of the method. In longterm future, the presented concept could also be used for controlled drug release. There, the marker solution would be replaced with a drug and specific degradation of the biopolymer would result in release of the medicine.

\section{ACKNOWLEDGMENT}

The authors acknowledge funding by FTP, project 211604-0011 on autonomous diagnostic arrays and the kind support of the cleanroom staff at DTU Danchip. They also thank senior researcher D. Plackett from DTU Risø for providing the biopolymer samples.

\section{REFERENCES}

[1] C. Bastioli ed., "Handbook of biodegradable polymers", Rapra Technol. Ltd., Shawbury, 2005

[2] Y. Tokiwa, A. Jarerat, "Biodegradation of poly(L-lactide), Biotechnol. Lett., 26, 771-777, 2004

[3] D. Haefliger, R. Marie, A. Boisen, "Self-actuated polymeric valve for autonomous sensing and mixing”, Proc. Transducers-'05, 1569-1572, 2005

[4] A. Johansson, G. Blagoi, A. Boisen, "Polymeric cantilever-based biosensors with integrated readout", Appl. Phys. Lett., 89, 2006

[5] M. Hopcroft, T. Kramer, G. Kim, K. Takashima, Y. Higo, D. Moore et al., "Micromechanical testing of SU-8 cantilevers", Fat. Fract. Eng. Mat. Struct., 28, 735-742, 2005

[6] S. Keller, D. Haefliger, A. Boisen, "Optimized plasma-deposited fluorocarbon coating for dry release and passivation of thin SU-8 cantilevers", J. Vac. Sci. Technol. B, 25, 1903-1908, 2007

[7] S. Keller, G. Blagoi, M. Lillemose, D. Haefliger, A. Boisen, "Processing of thin SU-8 films", J. Micromech. Microeng., 18, 125020125029,2008

[8] S. Keller, D. Haefliger, A. Boisen, "Fabrication of thin SU-8 cantilevers: Initial bending, release yield and time-stability," unpublished

[9] H. Klang, J.P. Kutter, O. Geschke, "CO2-laser micromachining and back-end processing for rapid production of PMMA-based microfluidic systems", Lab on a chip, vol. 2(4), pp. 242-246, 2002

[10] D. Cam, S.-H. Hyon, Y. Ikada, "Degradation of high molecular weight poly(L-lactide) in alkaline medium”, Biomaterials, 16, 833-843, 1995 